\title{
ДЕЯТЕЛЬНОСТЬ ЛЕКСИКОГРАФИЧЕСКИХ ЦЕНТРОВ
}

УДК 81374

DOI: $10.17223 / 22274200 / 13 / 8$

М.А. Бобунова

РУССКОЕ ФОЛЬКЛОРНОЕ СЛОВО В ЗЕРКАЛЕ СЛОВАРЯ (О ЛЕКСИКОГРАФИЧЕСКОМ ОПЫТЕ КУРСКИХ ЛИНГВОФОЛЬКЛОРИСТОВ)

Анализируется лексикографический опьт лингвофольклористов, работающุих над созданием словарей языка фольклора. Делается обзор лексикографической продукции курских исследователей, которые, наряду с традиционными формами, апробируют экспериментальные лексикографические формы (сжатый конкорданс, конкорданс одного слова, контрастивный словарь), имеюшие богатый исследовательский потенциал.

Ключевые слова: словарь, конкорданс, язык фольклора, фольклорная лексикография, лингвофольклористика.

В эпоху глобализации экономической и политической жизни обостряется интерес к истокам национальных культур, и прежде всего к фольклору. Данный интерес поддерживается и развивается разными способами: от переиздания ставших библиографической редкостью отдельных памятников устного народного творчества и создания полного академического Свода русского фольклора до компьютерной систематизации фольклорных архивов и формирования электронных баз данных. Опыт фольклористов постоянно обобщается, систематизируется и популяризируется на научных конференциях, посвященных проблемам изучения и сохранения традиционной культуры, а также на Всероссийском конгрессе фольклористов, где обсуждаются разные вопросы, связанные не только с теорией и историей фольклористики, но и с бытованием фольклора в современном информационном пространстве и сохранением нематериального культурного наследия России.

Одной из форм сохранения устного народного творчества является словарь, о целесообразности которого говорили еще в конце XIX в. 
Словарь как лаконичная форма представления разных данных в систематизированном виде привлекает разных специалистов. В частности, литературоведы смогли убедиться в достоинствах словарного описания языка с развитием писательской лексикографии. Еще в 1979 г. академик М.Л. Гаспаров, говоря о пушкинском словаре, так определил его значимость: «Словарь языка Пушкина» показал всем читавшим его, сколь многое в пушкинской семантике ускользало от нас, пока мы руководствовались чутким слухом и тонким вкусом и не думали о полноте и систематичности наших знаний [1. С. 27].

Конечно, устно-поэтическая лексика как часть национального языка находила и находит отражение в лингвистических словарях (толковых, диалектных, устаревших и редких слов и др.), однако объем таких наименований и степень их лексикографической обработки в разных типах справочников разнятся.

В толковых словарях специфические фольклорные единицы представлены в ограниченном количестве, а для их характеристики используются разные способы: толкование, ремарки, стилистические пометы (народно-поэт. и нар.-поэт. - народно-поэтическое слово или значение). Приведем примеры из «Словаря русского языка» под ред. А.П. Евгеньевой.

Баба-яга. В русских народных сказках: злая старуха-колдунья [2. C. 54].

Богатырь. Герой русских былин, воин, отличающийся необычной силой, удалью, мужеством и умом [2. С. 101].

Голубить. Народно-поэт. Ласкать, нежить, лелеять [Там же. С. 328].

Горюша. Народно-поэт. и обл. Горемыка [Там же. С. 337].

Гулливый. Народно-поэт. и прост. Любящий гулять, постоянно гуляющий [Там же. С. 356].

В диалектных словарях, в частности в «Словаре русских народных говоров», лексем, которые сопровождаются специальной пометой фольк. (фольклорное), значительно больше, однако и этот словарь не решает проблемы лексикографического описания слов, встретившихся в произведениях устного народного творчества. Хотя диалектные словари и используют в качестве одного из источников разные фольклорные сборники, в словник попадают не все лексические единицы того или иного текста, а прежде всего слова, территориально локализованные. 
Гадючинка. Фольк. Гадюка <.. > Тул., Шейн [3. С. 93].

Галань. Фольк. Гавань <...> Печор., Ончуков [Там же. С. 105].

Глотучий. Фольк. Эпитет к слову щука <...> Волог., 1877 [Там же.

С. 203].

Глумячий. Фольк. Шумливый < .. > Олон., 1887 [Там же. С. 212].

Гоголинка. Фольк. Утка [?] <...> Петрозав., Олон., Рыбников [Там же. С. 262].

Обратим также внимание на непоследовательность и несогласованность дефиниций и стилистического комментария как в пределах одного словаря, так и в разных словарях одного типа, что обусловлено объективной трудностью адекватного отражения семантической структуры народно-песенных лексем в неспециализированных лексикографических изданиях и сложностью разграничения фольклорного, областного, просторечного и устаревшего компонентов в семантике и структуре слова. Всё это постепенно утвердило лингвистов в мысли о необходимости создания специальных словарей языка фольклора, к созданию которых лингвофольклористы приступили в конце XX в.

Хорошо известно, что «русский фольклор по богатству, обилию материала, географическому разнообразию, сложности жанрового состава несравним ни с одним фольклором Европы и советского Востока» [4]. Это во многом определяет подходы лингвистов к лексикографическому описанию народно-песенной речи. Все чаще говорится о создании системы и серии словарей языка фольклора, базирующихся на определенных принципах: опора на жанровую дифференциацию материала, его территориально-временную однородность и учет специфичности семантической структуры фольклорного слова, требующей неординарного подхода и к формированию словников, и к непосредственному описанию отдельных языковых единиц.

Отсутствие традиции фольклорной лексикографии определило тактику словарной работы. На начальном этапе лингвофольклористы сконцентрировались на создании фиксирующих словарей (дающих списки языковых единиц без толкований) в двух вариантах: алфавитном и частотном. В частности, курские исследователи подготовили около 30 алфавитно-частотных словарей разных фольклорных жанров (былин, баллад, сказок, исторических песен, обрядовой и необрядовой лирики) (см., например: $[5,6])$. Позже на их базе стали создаваться конкордансы - алфавитные перечни всех слов источника с указанием контекстов их употребления. Основой для апробации лексико- 
графической формы конкорданса изначально стал семитомный свод А.И. Соболевского «Великорусские народные песни» как наиболее полное авторитетное собрание необрядовой лирики, записанной в XIX в. и систематизированной по жанрово-тематическому принципу (см., например: [7]).

Полные конкордансы, включающие все встретившиеся наименования, рассчитаны прежде всего на исследователей языка фольклора, которые найдут в них надежный фактический фундамент для изучения языка народной словесности. Хотя значимость конкорданса уже не подвергается сомнению, все же приведем цитату М.Л. Гаспарова из предисловия к российскому изданию «Конкоданса к стихам А.С. Пушкина» Дж.Т. Шоу: «В нем [конкордансе] на каждое слово и на каждую словоформу <... приводится полный текст всех фраз или всех стихотворных строк, в которых встречается это слово или эта словоформа. Все мельчайшие оттенки значения каждого слова выступают при этом так исчерпывающе ясно, как ни в каком словаре. Изучать по-настоящему язык и литературу, не имея таких конкордансов, невозможно» [8. С. III]. Полагаем, что эта мысль справедлива и по отношению к фольклорным конкордансам, которые дают объективное представление о качественном и количественном составе лексического яруса необрядовой лирики, бытовавшей на определенной территории России, и становятся своеобразными инструментами анализа фактического материала.

Кроме традиционной формы конкорданса, словарная статья которого включает заголовочное слово, статистическую информацию и исчерпывающее число контекстов с паспортизацией, курские исследователи апробировали форму сжатого (сконцентрированного) конкорданса, который является своеобразной «выжимкой» из иллюстративного материала. В этом случае в словарной статье приводится лишь один показательный контекст, а все синтагматические, парадигматико-синтагматические связи описываемой лексемы и ее участие в устойчивых поэтических приемах отражаются с помощью специальных условных обозначений тьи традиционного и сжатого конкорданса на материале онежских былин А.Ф. Гильфердинга [9].

${ }^{1} \boldsymbol{S}$ : связи с существительными; $\boldsymbol{A}$ : связи с прилагательными; Pron: связи с местоимениями; Num: связи с числительными; $\boldsymbol{V}$ : связи с глаголами; $\boldsymbol{A d v}$ : связи с наречиями; Voc: функция обращения; 五: ассоциативные ряды; $\boldsymbol{F}$ : поэтическая функция; +: дополнительная информация, комментарии. 
Гнездо 27. Подъезжае под гнездо да Соловьиное Того Соловья Рахматова (Калинин. Повенец. Илья МУРОМЕЦ И СОЛОВЕЙ РАЗБОЙНИК. Т. 1, № 3); Ты ставай-ко на резвы ноги, Ты вези-ко под гнездо да Соловьиное, Под того же было Соловья Рахматова! Подъезжае тут Илья да сын Иванович Под того же Соловья Рахматова, Под гнездо да соловьиное. Как подъехал Илья да сын Иванович Под гнездо да Соловьиное, Он натягивал свой тугой лук... (Калинин. Повенец. Илья МУРОМЕЦ И СОЛОВЕЙ РАЗБОЙНИК. Т. 1, № 3); Приезжает-то Илья ко той ли речки ко Черниговской, А он сльшит тут гнездо да Соловьиное (Фепонов. Пудога. ИЛЬЯ МУРОМЕЦ И СОЛОВЕЙ РАЗБОЙНИК. Т. 1, № 56); Ён спустил-то Соловья да на сыру землю, Пристсгнул его ко правому ко стремечки булатнему, Ен повез его по славну по чисту полю, Мимо гнездышко повез да Соловьиное. На том гнездышке да Соловьиноем А случилось быть да и три доче$p u$... (Рябинин. Кижи. ИЛЬЯ И СОЛОВЕЙ РАЗБОЙНИК. Т. 2, № 74); $B b$ зовите мужика да деревенщину, В своё гнездышко зовите Соловьиное, Да кормите его ествушкой сахарною, Да вы пойте его питьиием медвяныим, Да й дарите ему дары драгоиенные (Рябинин. Кижи. ИЛЬЯ И СОЛОВЕЙ РАЗБОЙНИК. Т. 2, № 74); А й зовут-то мужика да й деревенщину Во то гнездышко да Соловьиное... (Рябинин. Кижи. ИЛЬЯ И СОЛОВЕЙ РАЗБОЙНИК. Т. 2, № 74); Что свито у Соловья Рохманова Гнездо свито свое великое, Свито гнездо на двенадияати дубах, На двенадиати кокотищах И на пяти поприщах. Что мимо его гнезда воины не проезживали, Птицы не пролетывали... (Сарафанов. Кижи. ИЛЬЯ МУРОМЕЦ И СОЛОВЕЙ РАЗБОЙНИК. Т. 2, № 104); Подъезжал Илья Муромеи ко гнезду да соловьиному... (Сарафанов. Кижи. ИЛЬЯ МУРОМЕЦ И СОЛОВЕЙ РАЗБОЙНИК. Т. 2, № 104); Видит тут Соловей Рахманович, Что едет сильной храброй воин под гнездо соловьиное... (Сарафанов. Кижи. ИЛЬЯ МУРОМЕЦ И СОЛОВЕЙ РАЗБОЙНИК. Т. 2, № 104); И еще того сильнее пустился под соловьиное гнездо, И Соловей Рахманов высунул из гнезда своего буйну голову (Сарафанов. Кижи. ИЛЬЯ МУРОМЕЦ И СОЛОВЕЙ РАЗБОЙНИК. Т. 2, № 104); Лежит Добрыня о Почай-реку, А й ногамы лежит во Почай-реку, Кудрями лежит в част ракитов куст, Малолесны птички гнезда сповили Во Добрыниных во желтых кудрях (Суханов. Водлозеро. ДОБРЫНЯ И АЛЕША. Т. 3, № 206); Малолесны птички гнезда сповили Во Добрыниных во желтых кудрях (Суханов. Водлозеро. ДОБРЫНЯ И АЛЕША. Т. 3, № 206); Уж поехал тут казак да Илья Муромеи, Илья Муромеи да сын Иванович, Уж он едетто мимо то Соловьитое гнездышко (Федулов. Водлозеро. ИЛЬЯ 
МУРОМЕЦ И СОЛОВЕЙ РАЗБОЙНИК. Т. 3, № 212); Уж он едет мимо то Соловьитое гнездышко, Уж как глядят его рожоныи детушки <...> Уж как проезжают оны к Соловитому-то гнездышку, Он прибил то Соловитое-то гнездышко (Федулов. Водлозеро. ИЛЬЯ МУРОМЕЦ И СОЛОВЕЙ РАЗБОЙНИК. Т. 3, № 212); Да садился старой на добра коня Да поезжает старой ко Соловьиному ко гнездышко. Не доехал до гнезда да за три поприща, Усльххал Соловей-от разбойник-от... (Меншиков. Кенозеро. ИЛЬЯ МУРОМЕЦ И СОЛОВЕЙ РАЗБОЙНИК. Т. 3, № 274); Приезжае к Соловьиному гнездышку. У Соловья гнездо на двенадиати дубах (Меншиков. Кенозеро. ИЛЬЯ МУРОМЕЦ И СОЛОВЕЙ РАЗБОЙНИК. Т. 3, № 274); Увалился Соловей да со гнезда долой (Меншиков. Кенозеро. ИЛЬЯ МУРОМЕЦ И СОЛОВЕЙ РАЗБОЙНИК. Т. 3, № 274).

Гнездо (27) Видит тут Соловей Рахманович, Что едет сильной храброй воин под гнездо соловьиное (Т. 2, № 104) =: гнездышко ${ }^{1} 10$ А: свое великое $1, \mathrm{C}$ (с) оловьиное 14 , Солов (ь) итое $4 \mathbf{S}$ : г. у Соловья $1 \mathbf{V}_{\mathbf{s}}$ : <быть $>$ $1,<$ быть $>$ свито $2 \mathbf{V}_{\mathbf{0}}$ : везти под г. 1 , высунуть голову из г. 1 , ехать мимо г. 2, ехать под г. 1, звать в г. 2, не доехать до г. 1, не проезживать мимо г. 1, повезти мимо г. 1, подъезжать ко г. 1, подъезжать под г. 2, подъехать под г. 1, поезжать к г. 1, прибить г. 1, приезжать к г. 1, проезжать к г. 1, пуститься под г. 1, случилось быть в г. 1, слышать 1 , сповить 2, увалиться со г. 1 +: в 2 с/у гнездо птицы - Суханов (Водлозеро) «Добрыня и Алеша», в 25 с/у гнездо Соловья-разбойника; $C o$ лов(ь)итое гнездышко - Федулов (Водлозеро); прибить гнездышко Федулов (Водлозеро)

В первом случае конкорданс предлагает читателю собранные языковые факты, не навязывая их интерпретации, и оставляет простор

${ }^{1}$ В словаре онежских былин, картотека для которого составлялась нами в 90-е гг. $\mathrm{XX}$ в. вручную, слова с суффиксами субъективной оценки, многочисленные в фольклорном тексте, не выделялись в отдельную словарную статью, но обязательно учитывались в зоне вариантов. Исключение составляли случаи лексикализации диминутивов. Впоследствии, при создании конкордансов лирической песни с применением новых информационных технологий, уменьшительно-ласкательные наименования рассматривались нами уже в качестве самостоятельных словарных единиц, например: гнездо 2 и гнездушко 2 [7. С. 41]. Заметим, что подобные промежуточные категории всегда являются острой проблемой для лексикографов, которые предлагают разные подходы к её решению. 
для исследовательской мысли. Во втором же определенное лексикографическое «вмешательство» позволяет сразу сконцентрироваться на основных текстовых связях и функциях описываемого слова. Так, в онежском эпосе гнездо - это прежде всего место обитания Соловьяразбойника, о чем свидетельствуют атрибутивные и субстантивные связи существительного. Лишь в одной былине («Добрыня и Алеша») гнездо не связано с образом эпического существа, а оказывается неопровержимым аргументом, подтверждающим гибель Добрыни Никитича. Показательна и сочетаемость с глаголами, из которой ясно, что гнездо - это жилище, вокруг которого разворачивается действие, хотя в одном случае (в сочетании с глаголом прибить) сказитель Федулов использует слово в другом значении - 'семья, род, потомство'.

Обратим внимание на то, что в сконцентрированных конкордансах былинного текста предусмотрена дополнительно-информационная часть, в которой содержится указание на связь слова с территорией бытования, если это яркая региональная черта (возможно, что в скрытой форме здесь содержится указание на исполнительскую школу), идиолектом (принадлежностью к речи конкретного исполнителя) и сюжетом. Кроме того, эта зона словарной статьи включает в себя замечания собирателя или редактора текстов, отраженные в фольклорных собраниях, а также комментарии составителей словаря, связанные с толкованием слова и др. Приведем примеры из сжатого конкорданса онежских былин (кластер «Животный мир»).

Медвежий 10. Ах ты волчья сыть, медвежья выть! (1, № 3, 68) S: выть 2 , корм 1 , обед 3 , шерсть 4 ㅁ: волчий ... медвежий +: в формуле «понукание струсившего коня» [10. С. 94].

Олень 3. Шли туто четыре гнедые туры, Гнедые туры олени златорогие $(3$, № 258, 3) A: златорогий $3 \mathbf{S :}$ тур 3 +: Лядков (Кенозеро) «Василий Игнатьевич и Батыга». Туры олени златорогие - трижды в одном тексте [Там же. С. 96].

Пёс 17. Это ведь не старая собака, не седатый пёс, А это есте старый казак да Илья Муромец $(2$, № 114, 94) A: седатый 13, старый 3 S: борода 2, разбойник 1, собака 12 Voc: 12 +: только применительно к Илье Муромцу в формуле уничижительного обращения - прямого или косвенного [Там же. С. 96].

Рыкучий 8. Закричали звери тут рыкучии (2, № 152, 294) S: зверь 8 +: Кижи [Там же. С. 97]. 
С течением времени первые лексикографические опыты, показав перспективность изучения фольклорной картины мира с помощью лексикографических средств, вдохновили исследователей на поиск новых подходов и форм описания. Накопленный опыт создания традиционных и сжатых конкордансов привел нас к идее конкорданса одного слова [11]. Этот экспериментальный проект требовал особого отбора исходного наименования, в качестве которого было выбрано существительное печь. Наш выбор был обусловлен значимостью данного сооружения, которое всегда играло особую символическую роль во внутреннем пространстве дома и являлось одним из сакральных центров человеческого жилища [12. С. 310]. Полагая, что конкорданс одного слова может включать материалы разных фольклорных жанров, в пилотном выпуске мы ограничились текстами былин, необрядовой лирики, а также баллад и исторических песен, для которых характерно сочетание эпического и лирического начал.

Материалом описания конкорданса одного слова стали десять авторитетных былинных сборников, представляющих эпос Русского Севера, Урала, Сибири и Поволжья. В качестве источника необрядовой лирики был выбран семитомный свод «Великорусские народные песни». Базой эмпирического материала также стало авторитетное издание баллад серии «Библиотека русского фольклора», в котором тексты сгруппированы по тематическому принципу, а материалом описания исторических песен - академическое издание серии «Памятники русского фольклора», где песни расположены по сюжетам отдельных столетий.

Мы полагаем, что экспериментальная форма конкорданса одного слова обладает богатым исследовательским потенциалом, так как позволяет проводить межжанровое сопоставление для выявления общефольклорных и специфически жанровых черт, внутрижанровое сопоставление с учетом разных критериев: тематического, сюжетного, идиолектного и др. Кроме того, конкорданс дает возможность говорить о территориальной дифференциации языка фольклора как в рамках одного жанра, так и с учетом материала разных жанров, записанных на одной территории. На наш взгляд, любой пользователь словаря, в котором сконцентрированы разные текстовые фрагменты, позволяющие анализировать связи слов, их структуру и семантику, может найти в нем необходимый материал для описания многослойного образа русской печи в фольклоре. 
Одно из приоритетных направлений современных исследований изучение языка в контексте «диалога разных культур». Поскольку зеркалом культуры является язык, весьма показательными становятся работы в области межъязыковых сопоставлений. С.Г. Тер-Минасова пишет: «Язык - сокровищница, кладовая, копилка культуры. Он хранит культурные ценности - в лексике, в грамматике, в идиоматике, в пословицах, поговорках, в фольклоре, в художественной и научной литературе, в формах письменной и устной речи» [13. С. 14]. Следовательно, сравнение языковых единиц и фрагментов языковой картины мира разных народов может быть свидетельством этнической маркированности языковой системы. Так возникла идея создания контрастивного словаря языка фольклора, фрагмент которого представлен в приложении к кандидатской диссертации «Контрастивный словарь языка русского и английского песенного фольклора как база кросскультурного исследования» [14]. Такой экспериментальный словарь, имеющий особенности на макро- и микроструктурном уровнях, наглядно отражает разного рода асимметрию, а также выявляет концептуальную и лексическую лакунарность.

В работе на примере кластеров «Небо» и «Одежда» было показано, что словарная статья контрастивного словаря, представляющая собой «двухместную» лексикографическую ячейку, которая включает эквивалентные наименования, репрезентирующие один и тот же концепт, позволяет увидеть общие и специфические черты в языковой репрезентации конкретного фрагмента фольклорной картины мира. В частности, в английском песенном фольклоре отсутствуют слова, вербализирующие концепт «пояс», в то время как в русском это важный и обязательный компонент костюма (пояс, кушак, опояска), без которого находиться в обществе было грешно и неприлично.

Материалы контрастивного словаря позволяют говорить об отличиях в частоте употребления соотносительных наименований (количественная асимметрия), об особенностях их атрибутивных, субстантивных и глагольных связей (синтагматическая асимметрия). Выявляется даже культурная асимметрия, о чем говорит следующее наблюдение: «В английском фольклоре наименования одежды и тканей реже сочетаются с глаголами с семантикой дарения, в то время как в русской лирике перечень таких сочетаний разнообразен (дарить перчатки; дарить обновкой, ленточкой, платком; подарить шаль, юбку; даровать бархату, опояску, пожаловать платком; сулить кушак, 
перчатки, сапоги, плису на тулуп). Более прагматичные англичане высказывают лишь намерения о подарке в обмен на определенные действия со стороны девушки» [14. С. 171-172]. Таким образом, контрастивный словарь оказывается полезной формой для проведения кросскультурных исследований языка фольклора, имплицитно содержащего информацию о ценностных установках, характерных для разных наций и этнических групп.

В русской лексикографии давно утвердилось положение о том, что «адекватное и полное описание словарного состава языка невозможно осуществить в одном словаре, каким бы большим объемом он ни отличался» [15. С. 40]. Наш опыт в области фольклорной лексикографии подтверждает это. Мы полагаем, что разные виды словарей, разрабатываемых лингвофольклористами, будут способствовать всестороннему описанию устно-поэтического слова, специфика которого заставляет исследователей разных отраслей знания искать надежные средства для изучения данного феномена. Словарь оказывается одним из таких средств, в котором и фольклористы, и культурологи, и этнолингвисты найдут мощное эмпирическое подкрепление ранее сформулированных положений и хорошую источниковую базу для новых идей и разысканий.

\section{Лumepamypa}

1. Гаспаров М.Л. Филология как нравственность // Литературное обозрение. 1979. № 10. C. 26-27.

2. Словарь русского языка : в 4 т. / под ред. А.П. Евгеньевой. 3-е изд., стер. М. : Рус. яз., 1985. Т. 1.696 с.

3. Словарь русских народных говоров. Л. : Наука, 1970. Вып. 6.358 с.

4. Лихачев Д.С. Несколько замечаний о составлении свода русского фольклоpa. URL: http://rusfolklor.ru/archives/14115 (дата обращения: 15.05.2017).

5. Праведников С.П. Архангельские былины, собранные А.Д. Григорьевым: Мезень: Словник и частотный словарь. Курск : Изд-во Курск. гос. пед. ун-та, 2002. $63 \mathrm{c}$.

6. Праведников С.П. Песни, собранные П.Н. Рыбниковым: словник. Курск : Изд-во Курск. гос. ун-та, 2006. 70 с.

7. Бобунова М.А., Хроленко А.T. Конкорданс русской народной песни: Песни Курской губернии. Курск : Изд-во Курск. гос. ун-та, 2007. 258 с.

8. Гаспаров М.Л. Предисловие к российскому изданию // Шоу Дж.Т. Конкорданс к стихам А.С. Пушкина. Т. 1 (А-Н). М., 2000. 662 с.

9. Онежские былины, записанные А.Ф. Гильфердингом летом 1871 года : в 3 т. 2-е изд. СПб., 1894-1900. Т. 1-3. 
10. Бобунова М.А., Хроленко А.Т. Словарь языка русского фольклора: Лексика былины. Ч. 1: Мир природы. Курск : Изд-во Курск. гос. ун-та, 2006. 125 с.

11. Бобунова М.А. Печь нам мать родная: опыт конкорданса одного слова. Курск : Изд-во Курск. гос. ун-та, 2014. 80 с.

12. Славянская мифология: энцикл. слов. М. : Эллис Лак, 1995. 416 с.

13. Тер-Минасова С.Г. Язык и межкультурная коммуникация. М. : Слово / Slovo, 2000. 624 c.

14. Бобунов A.M. Контрастивный словарь языка русского и английского песенного фольклора как база кросскультурного исследования : дис. ... канд. филол. наук. Курск, 2012. 262 с.

15. Сороколетов Ф.П. Традиции русской советской лексикографии // Вопросы языкознания. 1978. № 3. С. 26-42.

\section{THE RUSSIAN FOLKLORE WORD AS REFLECTED IN DICTIONARIES (CONCERNING THE LEXICOGRAPHIC EXPERIENCE OF LINGUOFOLK- LORISTS FROM KURSK)}

Voprosy leksikografii - Russian Journal of Lexicography, 2018, 13, pp. 141-153.

DOI: $10.17223 / 22274200 / 13 / 8$

Mariya A. Bobunova, Kursk State University (Kursk, Russian Federation). E-mail: bobunova61@mail.ru

Keywords: dictionary, concordance, folklore language, folklore lexicography, linguofolkloristics.

The article describes the lexicographic experience of linguofolklorists working on folklore language dictionaries compilation. The Russian folklore is distinguished by the complexity of genre composition, geographic diversity and abundance of materials, which determines the approaches of linguists to lexicographic description of the folk song language. We often hear about the creation of a system and a series of folklore language dictionaries which have certain principles.

Since there had been no tradition in folklore lexicography the following tactics was adopted. Firstly, linguofolklorists focused on compiling register dictionaries of two types: alphabetic and frequency dictionaries. The researchers from Kursk have compiled approximately 30 alphabetic-frequency dictionaries of different folklore genres. Later these dictionaries gave way to creating concordances - alphabetic listings of all the words from the text under analysis including the contexts of their usage. In addition to the traditional concordance form (the entry consists of the core word, statistic data and contexts with passportization), researchers from Kursk have tested the form of the concentrated concordance which is a sort of "essence" of the illustrative material. In this case, we observe an entry with one demonstrative context; the syntagmatic, paradigmatic and poetic device links of the analyzed lexeme are presented by means of specially adopted symbols.

The experience with traditional and concentrated concordances led to the development of the one-word-concordance. This experiment required a special choice of the initial nomination. The choice fell on the noun "stove" due to its high symbolic importance for every house. The one-word-concordance presumably may comprise mate- 
rials of different folklore genres; thus, researchers from Kursk took the texts of bylinas and non-ritual lyrics as well as ballads and historical songs (these sources combine both epic and lyrical moods) as the basis of their pilot project.

Cross-cultural language studies have become a high priority trend of modern research. The contrastive dictionary of folklore language has become an original idea. This dictionary consists of entries which are double lexicographic units comprising equivalent nominations, which enables researchers to see common and specific traits in language representation of a certain fragment of the picture of the world in different cultures.

The conclusion focuses on the significance and scientific reliability of dictionaries of different kinds in the study and comprehensive description of folklore.

\section{References}

1. Gasparov, M.L. (1979) Filologiya kak nravstvennost' [Philology as morality]. Literaturnoe obozrenie. 10. pp. 26-27.

2. Evgen'eva, A.P. (ed.) (1985) Slovar' russkogo yazyka: v 4 t. [Dictionary of the Russian language: in 4 vols]. 3rd ed. Vol. 1. Moscow: Rus. yaz.

3. Filin, F.P. \& Sorokaletov, F.P. (1970) Slovar' russkikh narodnykh govorov [Dictionary of Russian folk dialects]. Is. 6. Leningrad: Nauka.

4. Likhachev, D.S. (n.d.) Neskol'ko zamechaniy o sostavlenii svoda russkogo fol'klora [A few comments on the compilation of the Russian folklore]. [Online] Available from: http://rusfolklor.ru/archives/14115. (Accessed: 15.05.2017).

5. Pravednikov, S.P. (2002) Arkhangel'skie byliny, sobrannye A.D. Grigor'evym: Mezen': Slovnik i chastotnyy slovar' [Arkhangelsk epics, collected by A.D. Grigoriev: Mezen: A glossary and a frequency dictionary]. Kursk: Kursk State Pedagogical University.

6. Pravednikov, S.P. (2006) Pesni, sobrannye P.N. Rybnikovym: slovnik [Songs collected by P.N. Rybnikov: a glossary]. Kursk: Kursk State University.

7. Bobunova, M.A. \& Khrolenko, A.T. (2007) Konkordans russkoy narodnoy pesni: Pesni Kurskoy gubernii [Concordance of Russian folk song: Songs of Kursk province]. Kursk: Kursk State University.

8. Gasparov, M.L. (2000) Predislovie k rossiyskomu izdaniyu [Foreword to the Russian edition]. In: Shaw, J.T. Konkordans k stikham A.S. Pushkina [Concordance to the verses of A.S. Pushkin]. Vol. 1. Moscow: Yazyki russkoy kul'tury.

9. Hylferding, A.F. (1894-1900) Onezhskie byliny, zapisannye A.F. Gil'ferdingom letom 1871 goda: $v 3 t$. [The Onega epics recorded by A.F. Hylferding in the summer of 1871: in 3 vol]. 2nd ed. St. Petersburg: tip. Imp. Akad. nauk.

10. Bobunova, M.A. \& Khrolenko, A.T. (2006) Slovar' yazyka russkogo fol'klora: Leksika byliny [Dictionary of the language of Russian folklore: Vocabulary of the byliny]. Pt. 1. Kursk: Kursk State University.

11. Bobunova, M.A. (2014) Pech' nam mat' rodnaya: opyt konkordansa odnogo slova [The stove is our mother: the experience of concordance of one word]. Kursk: Kursk State University. 
12. Petrukhin, V.Ya. (ed.) (1995) Slavyanskaya mifologiya: entsikl. slov. [Slavic mythology: an encyclopedic dictionary]. Moscow: Ellis Lak.

13. Ter-Minasova, S.G. (2000) Yazyk i mezhkul'turnaya kommunikatsiya [Language and intercultural communication]. Moscow: Slovo.

14. Bobunov, A.M. (2012) Kontrastivnyy slovar' yazyka russkogo i angliyskogo pesennogo fol'klora kak baza krosskul'turnogo issledovaniya [Contrastive dictionary of the language of Russian and English song folklore as a basis for cross-cultural researc]. Philology Cand. Diss. Kursk.

15. Sorokoletov, F.P. (1978) Traditsii russkoy sovetskoy leksikografii [Traditions of Russian Soviet lexicography]. Voprosy yazykoznaniya. 3. pp. 26-42. 